\title{
Idiopathic Hypereosinophilic Syndrome with a Radiologic Pattern of Central Pontine Myelinolysis
}

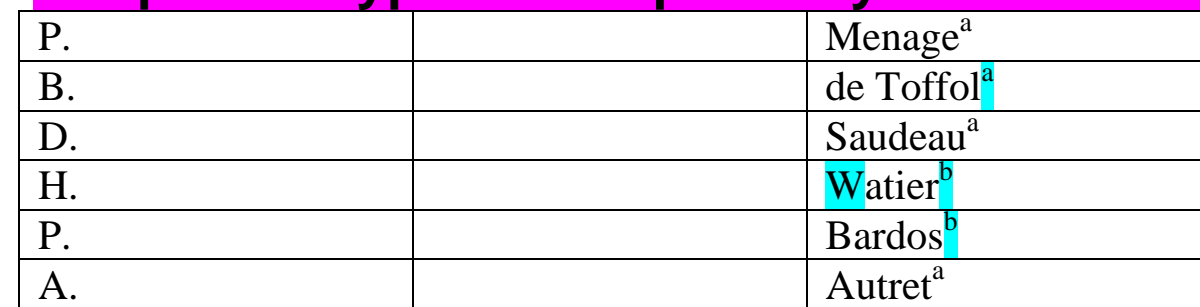

${ }^{\mathrm{a}}$ Clinique Neurologique, Hôpital Bretonneau et ${ }^{\mathrm{b}}$ Laboratoire d'Immunologie, Faculté de Médecine, Tours, France

\section{Dr P. Menage, Clinique Neurologique, 2, bd. Tonnellé, F-37044 Tours Cedex (France)}

The idiopathic hypereosinophilic syndrome (HES) is defined by the presence of hypereosinophilia (\&gt; 1,500 cells/mm3) coupled with visceral manifestations without any known cause for more than 6 months [1]. We report a patient with HES who had axonal sensorimotor polyneuropathy and radiologic abnormalities resembling central pontine myelinolysis.

Case Report

A 70-year-old man was hospitalized in November 1991 following the progressive appearance of paresthesias, myalgias, muscular weakness and a 15 kg weight loss. Hypereosinophilia (4,272 cells/mm3) was noticed in June. The physical examination revealed a polyneuropathy predominating in the lower limbs with unability to stand erect. Sensory loss consisted of paresthesias, hyperesthesia to touch, distal hypoesthesia and loss of position sense in the toes.

Cutaneous plantar reflexes were indifferent. Proprioceptive ataxia, agnosia to touch and dysphonia were noted.

White cell count showed 28,000 cells/mm3 (normal, N : 4-10 x 103) with 53\% eosinophils and 41\% polymorphonucleocytes; CD3+, 2,520 cells/mm3 (N: 1,650 \pm 450); CD4+, 1,135 cells/mm3 (N: $880 \pm$ 230); CD8+, 1,260 cells/mm3 (N: $700 \pm 200)$. Soluble CD25 (2,096 IU/ml, N \&lt;800) was increased with a majority (90\%) being activated hypodense eosinophils. Sodium (141 mEq/1, N: 135-145), serum creatinine, CPK and cerebral spinal fluid were normal. The electromyogram demonstrated diffuse axonal motor impairment with conservation of the motor conduction velocities; sensory potentials were absent. A peripheral nerve biopsy showed a CD8+ T cell infiltration of peri- and endoneuronal vessel walls associated with almost complete demyelinization and axonal loss. Biopsy of the right anterior tibialis muscle demonstrated periarterial and endomyseal CD8+ T cell infiltration. Somesthetic evoked potentials of the lower limbs were absent and abnormal in the upper limbs (ERb’s point and cervical spinal cord potentials were normal, latency of PI 5 and N20 waves was increased). Brain MRI showed a diffuse hyposignal in Tl-and hypersignal in T2-weighted sequences (fig. 1) over the central pontine region. Exhaustive etiological investigations [2] were negative.

Treatment initiated in December 1991 consisted of exchange transfusion followed by monthly intravenous cyclophosphamide (750 mg/m2) and methylprednisolone (250 mg). In November 1992, physical examination revealed a $10 \mathrm{~kg}$ weight gain, a slight distal motor defect in all four extremities. Eosinophil count (250 cells/ mm3) was normal, pontine abnormalities in MRI were unchanged.

Discussion

Peripheral neuropathy during HES is seen in 6-14\% of the patients and is most often axonal [ 1]. In our case, the polyneuropathy appeared to be secondary to a T CD8+ infiltration related to a peripheral increase in the number of CD8+ T lymphocytes as well as activated hypodense eosinophils. These findings are different from 


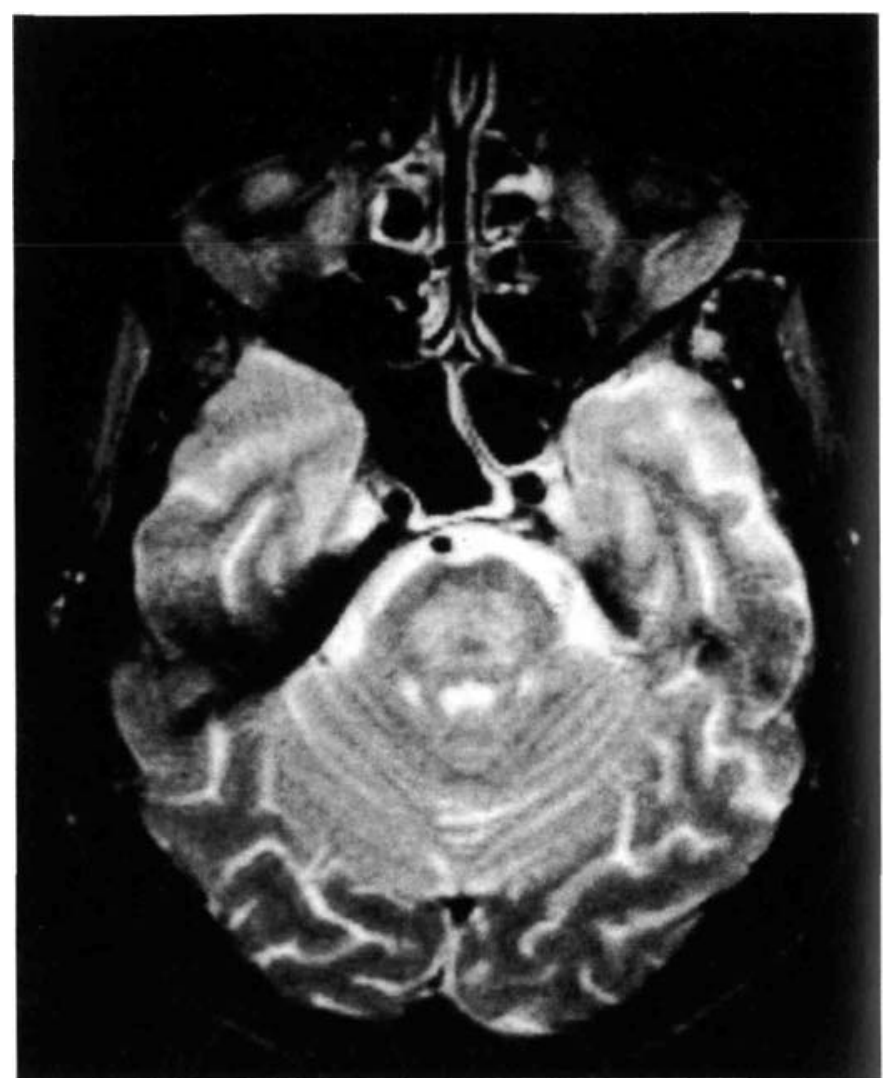

Fig. 1. Brain MRI. Central pontine region. Horizontal section. Diffuse hypersignal in T2-weighted sequences. those reported in the literature: axonal lesions with endo- and peri-neuronal vascular destruction and interstitial edema [3]; intravascular or endomyseal eosinophilic infiltration [4]. Intracranial lesions are rarely observed [1]. In our case, brain MRI findings suggested a central pontine myelinolysis, not previously been reported in HES.

We can suggest that myelinolysis could be related: (1) to a microangiopathy responsible for ischemia in usual cerebral abnormalities; (2) to Gordon's phenomenon considered to be an experimental model of the neurotoxicity of eosinophils [5]; (3) to a direct effect of the eosinophils or neurotoxic factors secreted by activated hypodense eosinophils responsible for thromboembolic events and/ or endothelial and epitelial lesions [6-8].

In addition, treatment consisting of monthly boluses of methylprednisolone and cyclophosphamide [2,9] was followed by remission of the HES.

References

Chusid MJ, Dale DC, West BC, Wolff SM: The hypereosinophilic syndrome: Analysis of fourteen cases with review of the literature. Medicine 1975;54:1-27. Guillevin L, Prin L, Bletry O: Syndrome hypereosinophilique; in Kahn MF, Peltier AP, Meyer O, Piette JC (eds): Les maladies systemiques. Paris, Flammarion, 1991, pp 1041-1057.

Monaco S, Lucci B, Laperchia N, et al: Polyneuropathy in hypereosino-philic syndrome. Neurology 1988;38:494-496.

Dorfman LJ, Ransom BR, Forno LS, Kelts A: Neuropathy in the hypereo-sinophilic syndrome. Muscle \& Nerve 1983;6:291-298.

Durack DT, Klebanoff S, Sumi SF: Neurotoxicity of human eosinophils. Proc Natl|Acad Sci USA 1979;76:1443-1447.

Wichman A, Buchthal F, Pezeshpour GH, Fauci AS: Peripheral neuropathy in hypereosinophilic syndrome. Neurology 1985;35:1140-1145.

Venge P, Dahl R, Hallgren R, Olsson I: Cationic proteins of human eosinophils and their role in the inflammatory reaction; in Mahmoud AAF, Austen KF (eds): The Eosinophil in Health and Disease. New York, Grune \& Stratton, 1980, pp 131-144.

Ackerman SJ, Loegering DA, Venge P: Distinctive proteins of the human eosinophil granule: Major basic protein, eosinophil cationic protein and eosinophilderived neurotoxin. J Immunol 1983;131:2977-2982.

Moore PM, Harley JB, Fauci AS: Neurologic dysfunction in the idiopathic hypereosinophilic syndrome. Ann Intern Med 1985;102:109-114. 